\title{
Analyzing with Posner's Conceptual Change Model and Toulmin's Model of Argumentative Demonstration in Senior High School Students' Mathematic Learning
}

\author{
Y. T. Chen and J. H. Wang
}

\begin{abstract}
The researcher aimed to study how through dialogue, the concept ecology of each individual was made unstable and thus facilitated conceptual change and further achieved concept learning. Later, using the model proposed by Toulmin, the researcher analyzed the argumentative performances of the three students in their discussion. The data collected in this research include worksheets and the transcription of the video records of the students' learning. The findings of the research revealed that 1) teaching is not just a means to inform or to demonstrate the use of knowledge to students; teachers must encourage students to create meaning through autonomous contemplation and deduction, reasoning and communication, 2) only by unbalancing the students' ecological concepts will they modify their present concept structure. Furthermore, the students' demonstration orientation includes an intuitive experience and examples of argumentation, form theory argumentation. Therefore, apart from preparing appropriate argumentative questions for students, teachers should further encourage students to think and create an argumentative atmosphere, which could elevate the significance of in-class learning.
\end{abstract}

Index Terms-Cooperative learning, mathematical conceptual learning, conceptual change model, argumentative model.

\section{INTRODUCTION}

As Constructivism and cognitive psychology gradually gain their position in the eyes of mathematics educators, the construction of knowledge has transformed from the conventional teacher-centered education to the emphasis of autonomous, student-centered learning. The goal of mathematics education is to have students truly understand mathematical concepts rather than mere mechanical memorization and recitation. Therefore, communication and discussion among peers are emphasized to boost students' conceptual construction and transformation. However, after years of teaching, the researcher realized that students do not go to their classes empty-headed. In fact, before they enter the classroom, they had already constructed a framework regarding the concept they learn in class from their own personal experiences; and the accuracy and correctness of this

Manuscript received October 10, 2014; revised December 19, 2014

Y. T. Chen is with the Department of Mathematics Education, National Taichung University, No.140, Minsheng Rd., West Dist., Taichung City 40306, Taiwan (R.O.C.) (e-mail: ytchen@mail.ntcu.edu.tw ).

J. H. Wang is with the Graduate Institute of Educational Administration and Policy Development, National Chiayi University, No.85, Wunlong Village, Minsyong Township, Chiayi County 621, Taiwan (R.O.C) (e-mail: gloriawang2004@mail.ncyu.edu.tw). concept structure varies from person to person. As a mathematics teacher, the researcher feel responsible to amended and extend students' concept structure, and only then can they really learn.

In view of this, the researcher referred to the Student's Team Achievement Division (STAD) theory [1] and designed a cooperative learning environment in a high school freshmen classroom. In this context, the researcher hoped the students' ecological concepts would become unstable through meaningful dialogue which could promote individual conceptual change and ultimately achieve effective learning. This was one of the research motivations. Moreover, the researcher was curious about what theory basis did the students refer to when persuading their peers during the course of the dialogues? What arguments did they put forth to convince their peers and to support their claims? In the study of the logical structure of argumentation, Toulmin (1958) [2] proposed "D-W-C" demonstration mode, which can be used to understand the primary cause of students' different interpretation of the same phenomenon and help teachers realize individual student takes different view base on different theories and arguments. This is the second research motivation.

Based on the above research motivation, this study drew upon Posner's [3] conceptual change model and Toulmin's (1958) [2] demonstration mode and aimed to high study school students' mathematical concepts learning in a cooperative learning context. The research proposes were as follows:

1) Understand how students' mathematical concepts changed in the cooperative learning context.

2) Explore possible mechanisms that promote students' mathematical conceptual change.

3) Study students' demonstrated performances in the cooperative learning context.

4) Examine the tendency of students' demonstrative performance

\section{Procedure FOR PAPER SUBMISSION}

For the purposes of this study, the researcher first discussed the conditions and theory of conceptual change based on the theories of Posner, Strike, Hewson, and Gertzog (1982) [3]; secondly, the researcher elaborated on Toulmin's (1958) [2] "D-W-C" demonstration mode and applied it as the theoretical basis of this study.

\section{A. Theory of Conceptual Change Conditions}


From personal teaching experience the researcher discovered: when students first entered the classroom, they already held certain mathematical concepts that they accumulated mainly from real life experiences. Therefore, to stimulate students' conceptual change, teachers cannot just tell their students the correct ideas. Posner, Strike, Hewson, and Gertzog (1982) [3] published paper regarding necessary conditions for conceptual change model - these conditions must fully satisfied to enable students' conceptual change. These conditions include dissatisfaction, intelligible, plausibility, and fruitfulness. The introduction of these conditions is as follows:

\section{1) Dissatisfaction}

It did not seem easy for students to abandon their original concept, unless they had good reason to doubt it. Sometimes, direct observation was easier to arouse dissatisfaction among students toward their own concepts. However, the "dissatisfaction" was not the only condition to conceptual change [4], [5], other conditions are also required.

\section{2) Intelligible}

If no reasonable explanations were given, students would either consider "correcting" their existing concept or ignore the difficult problem and maintain their original concept [4]. Thus, Hewson (1996) [6] proposed that in order to make the students believe the concept to be intelligible, these questions must be answered: did the learner understand its means? Could the learner find a way to represent this concept? In other words, if the learners found this concept understandable and easy to comprehend, they must be able to explain and to present this concept in ways they were familiar with instead of mere repetition of what the teacher taught.

\section{3) Plausibility}

Even when comprehensible examples were provided for explanation, students would still fail to understand if the given example seemed unreasonable to them. Therefore, Hewson (1996) [6] proposed: to make students think a concept is plausible, it was crucial to know whether learners find the concept true. Was this concept consistent with other concepts the learners accepted? In other words, to make the learners feel credible and reasonable, the concept must coordinate, without any conflict, with what learners had already accepted.

\section{4) Fruitfulness}

This required the learners to discard their original idea and switch to another view. Therefore, Hewson (1996) [6] proposed: to make learners think this concept is fruitful, one must question what value did the learners gain from it? Could it answer problems that learners failed to solve? Did it give learners a new direction or idea? That was to say, to make learners think a concept is reasonable and beneficial, it must be able to solve problems that other concepts they gained in the past could not, and make learners realize the benefits of this concept.

In view of this, Hewson (1996) [6] referred to the above three conditions - intelligible, plausible and fruitful as " a person's concept status." This conceptual ecological followed a sequential procedure in the formation of a new concept that started from intelligible to reasonable, plausible, and fruitful. The learning of a new concept indicated the enhancement of one's conception status. However, these three dimensions were absolutely not the only means that would influence conceptual change; personal knowledge, meta-belief, learning motivation, etc. amassed to affect learners' concept learning.

The overall dimensions were what Hewson (1996) [6] called the Conceptual ecology.

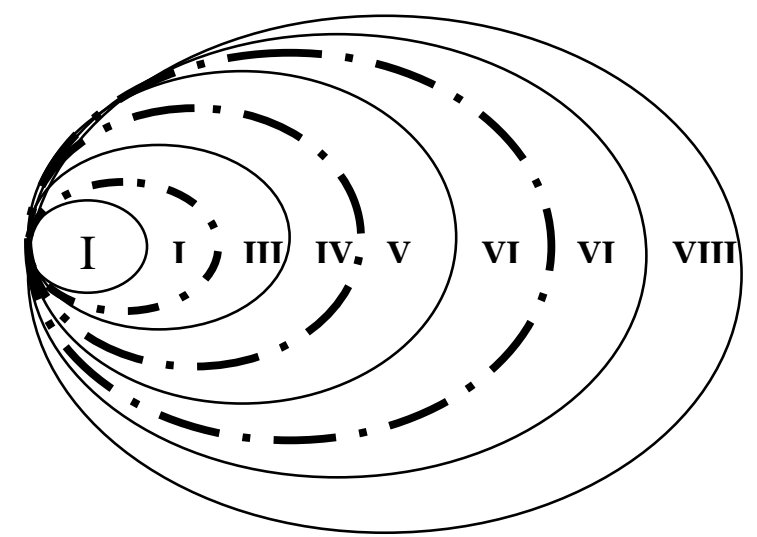

I. Primitive Knowing; II. Image Making; III. Image Having; IV. Property Noticing; V. Formalizing; VI. Observing; VII. Structuring; VIII. Inventing Fig. 1. Growth of mathematical understanding model.

Pirie (1994) [7] defined mathematical understanding as a dynamic, nonlinear, and recursive mathematical process to organizing knowledge structure. The growth of mathematical understanding occurred between individuals and others around them, such as teacher-student interaction. It included internal and external interactions [8]. So, she introduced the following model (Fig. 1) to characterize mathematical understanding.

The researcher believed that the conceptual change theory [4] and the dynamic, nonlinear, and recursive characteristics in the mathematical understanding theory [8] had great similarities. Thus, the researcher applied Pirie's mathematical understanding model to characterize Posner's graphic of conceptual change ecology (Fig. 2).

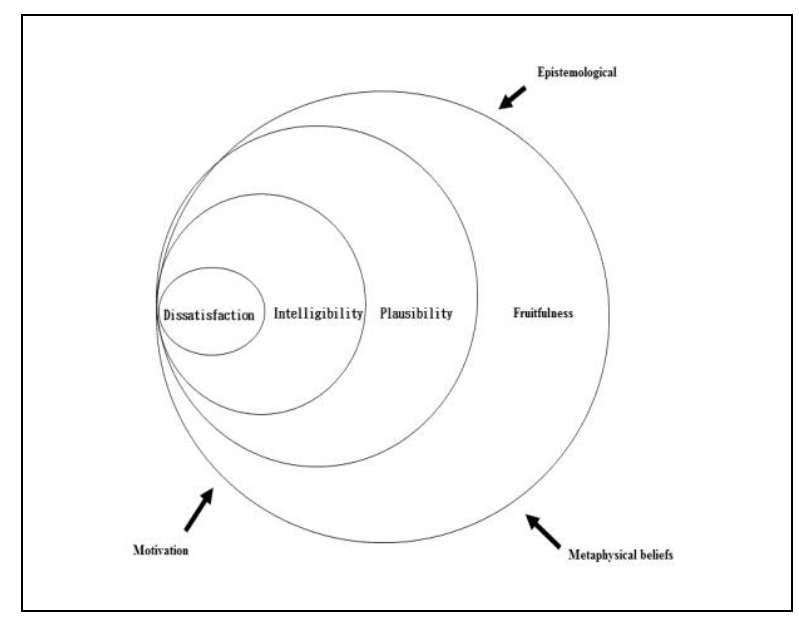

Fig. 2. Graphic of conceptual change ecology.

\section{B. Toulmin's $\lceil D-W-C\lrcorner$ Demonstration Model}

Following the discussion of conceptual change conditions came the question of how could teachers create an environment that was easy for conceptual learning or conceptual change for students. How did the research analyze students' conceptual change and learning conditions? In fact, how students understand mathematics concepts in class has 
always been an important issue [9]. Many researchers like Confrey (1994) [10] and Labinowicz (1985) [11] emphasized that: the best way to learn mathematics is for students to actively engage in their own study. From this perspective, "a classroom which provides students an autonomous learning environment" is the best for students to learn mathematics [12]. However, in the study of argumentative logical structure, Toulmin (1958) [2] proposed the "D-W-C" demonstration mode (Fig. 3). In this mode, the "D" stood for "Data" or information collected from observing external phenomenon; "W" referred to the "Warrant" used for evidence when making inferences; "C" was the "Conclusion" reached through deduction. These were the most elementary elements of demonstration framework. Toulmin (1958) [2] further pointed out: a rational argument consist the four components: data warrant, supporting theories, and conclusion. When scientists structure their arguments, they typically offer large amounts of data (D), and propose an argument or reach a conclusion (C) based on these collected data. They were expected to defend their conclusions based on the warrant (W), and these inferences usually have theory backing (B) for interpretation. However, when it came to the distinction between warrant $(\mathrm{W})$ and theory backing $(\mathrm{B})$ when, Toulmin explained that: theory backing usually remains self-evident, it was prior to argumentation, and existed before it was even challenged.

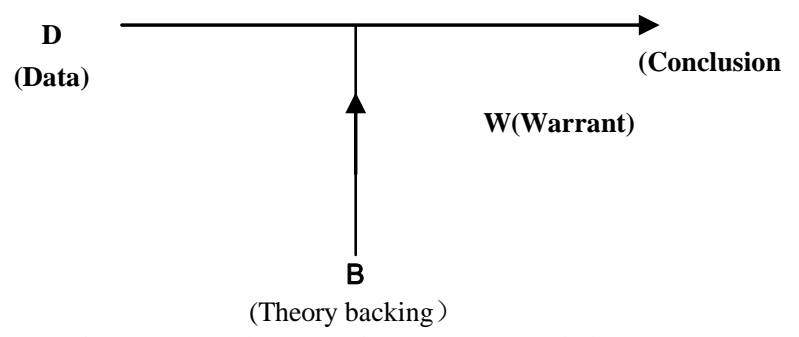

Fig. 3. D-W-C demonstrative structure (Toulmin 1958).

Toulmin further proposed that: whether an argument was valid or not, greatly depended its Theory backing (B). Toulmin's argumentation model showed that the primary cause to different interpretations of the same phenomena was the diverse supporting theories provided by different individuals, and therefore invoked discrepancy in understanding and interpretation.

In this research, the participating students were first placed in a "cooperative learning" classroom context; later, the students were engaged in discussions to familiarize with cooperative learning, and achieve mathematic concept learning through dialogues. The researcher drew on Posner's conceptual change model and Toulmin's argumentation theory to analyze the classroom conversation, and aimed to understand students' conceptual learning and change through dialogic argumentation.

\section{MethodOLOGY}

The data collected in this study came mainly from classroom observation and document analysis. Classroom observation included video and audio records of the participants' learning conditions in the cooperative learning context. Additional field notes were taken by the researcher.
Document analysis focused on the analysis of student's worksheet performances.

\section{A. Participants}

The main participants of this study included the researcher 1 (R1) and the three first-year high school students the researcher was teaching. As for the second researcher (R2) took the role as the inquirer and dealt with triangulation and meta-analysis. The students participating in this study were three female first-year high school students who were under the instruction of R1, and were chosen through convenience sampling. Their performances on the high school entrance examination were above average level in the area. The description of R1, R2 and the participating students are as follows:

\section{1) Researcher $1(R 1)$}

R1was a Master in Mathematics Education and had four and five years teaching experiences each in senior and in junior schools. During the research period, the researcher created a cooperative learning context for the first-year high school students who were under his instruction. He designed suitable learning materials for his students as the "teacher," and studied the students' learning performances as the "observer."

\section{2) Researcher $2(R 2)$}

Researcher R2 was a professor in a teacher education institution. During the research period, R1 transcribed the video records collected from the classroom context, while R2 reviewed the videotapes and the transcribed text to determine the plausibility of R1's conclusions. The triangulation was conducted to ensure the reliability of this study.

\section{3) Students}

The students participating in this study were three female first-year high school students who were under the instruction of R1, and were chosen through convenience sampling. Their performances on the high school entrance examination were above average level in the area.

\section{B. Measurement Tool}

The measurement tools used in this study was the worksheet on "integers" drawn from the "numbers and coordinate system" chapter in the teacher's handbook (Nani). Each question contained a teaching objective and therefore ensured its content validity. The following chart (Table I) is the qualitative analysis of the worksheets and afterward assessments.

\begin{tabular}{lll}
\hline & \multicolumn{2}{c}{ TABLE I: WORKSHEET ANALYSIS } \\
\hline Worksheet & Question & Content \\
\hline Integers & 1 & $\begin{array}{l}\text { Understanding integer division, } \\
\text { especially: } 0<\text { remainder }<\mid \text { divisor } \mid\end{array}$ \\
\cline { 2 - 3 } & 2 & $\begin{array}{l}\text { Understanding the contrasting idea of } \\
\text { factors and multiples, and their } \\
\text { properties. }\end{array}$ \\
\hline
\end{tabular}

Accordingly, the worksheet used in this research was reviewed and amended by two senior professors and a professor from teacher education institution (Table II):

\section{Research Validity Analysis}

This research aimed to understand student's conceptual 
change process, and thus drew on Posner's conceptual change model for data analysis. However, in order to clarify the transformation process, an assessment test was required. Accordingly, the researcher formed a criterion in the analyzing students' conceptual learning and change (Table III), and hoped to present the validity of this research.

TABLE II: WORKSHEET QUESTIONS

\begin{tabular}{ll}
\hline Learning purpose & Question \\
\hline $\begin{array}{l}\text { Understanding } \\
\text { integer division, } \\
\text { especially: }\end{array}$ & $\begin{array}{l}\text { Given the Division Axiom: } \\
\text { Solve: }\end{array}$ \\
$\begin{array}{l}0 \leqslant \text { remainder }< \\
\text { divisor| }\end{array}$ & $\begin{array}{l}\text { (1) The quotient and remainder of } 31 \text { divided by } 4 \\
\text { (2) The quotient and remainder of } 100 \text { divided by } \\
-13\end{array}$ \\
\hline $\begin{array}{l}\text { Understanding the } \\
\text { contrasting idea of } \\
\text { factors and multiples } \\
\text { and their properties. }\end{array}$ & $\begin{array}{l}\text { a, } \mathrm{b}, \mathrm{c} \in \mathrm{N}, \text { If a } \mid \mathrm{bc}, \text { then were } \mathrm{a} \mid \mathrm{b} \text { or alc true? } \\
\end{array}$ \\
\hline
\end{tabular}

\begin{tabular}{ll}
\multicolumn{2}{c}{ TABLE III CRITERION FOR STUDENTS' CONCEPTUAL CHANGE ANALYSIS } \\
\hline Conditions & \multicolumn{1}{c}{ Criterion } \\
\hline Dissatisfaction & \multicolumn{1}{c}{ Students began to doubt their original concepts. } \\
\hline Intelligible & $\begin{array}{l}\text { Learners found this concept intelligible and } \\
\text { comprehensible. They can explain and represent } \\
\text { this concept in ways familiar to them instead of } \\
\text { repeating the content the teacher's lecture. }\end{array}$ \\
\hline Plausibility & $\begin{array}{l}\text { Learners found this concept intelligible and } \\
\text { plausible. This concept must coordinate with } \\
\text { learners' present concepts without any conflicts. }\end{array}$ \\
\hline Fruitfulness & $\begin{array}{l}\text { Learners abandoned the original concepts. } \\
\text { Learners found this concept plausible and fruitful. } \\
\text { This concept must be able to solve problems that } \\
\text { learners' original concepts could not, and made } \\
\text { them realize its usefulness. }\end{array}$ \\
\hline
\end{tabular}

To ensure the research reliability, researcher 1 (R1) gave the transcription to researcher 2 (R2) to review and determine the plausibility of the conclusion. When the two researchers were in disagreement, further negotiation and discussions were undertaken to reach a consensus and to guarantee the research reliability through this triangulation. Examples were given below (Table IV).

\begin{tabular}{|c|c|c|}
\hline Corpus & Researcher1anotation & $\begin{array}{l}\text { Coordinate } \\
\text { Researcher R2 }\end{array}$ \\
\hline $\begin{array}{l}\text { D9109221001: the } \\
\text { first question is easy! } \\
4 \text { times } 7 \text { is } 28,4 \\
\text { times } 8 \text { is } 32 \ldots \text { so } 31 \\
\text { divided by } 4 \text { is } 7 \text { and } \\
\text { the remainder is } 3 \text {. } \\
\text { D9109223001: } \\
\text { Yeah...right. } \\
31 \text { equals } 4 \text { times } 7 \\
\text { plus } 3 \ldots \text { so the } \\
\text { remainder is } 3 \text {. }\end{array}$ & $\begin{array}{l}\text { [1W: think with } \\
\text { examples — B: Division } \\
\text { Axiom_ intelligible] }\end{array}$ & -Agree $\square$ Disagree \\
\hline
\end{tabular}

\section{DATA ANALYSIS AND DISCUSSION}

For the purposes of this study, the researchers first report on students' learning performance on the integer unitstudents' argumentation process when solving the test questions, the concept they learned, and what conceptual change occurred. Secondly, the researchers hoped to find potential mechanisms that influenced students' mathematics concept learning and conceptual change and what promoted students' argumentation behavior. Hereby were separately described below.

\section{A. Students'Mathematics Concept Learning, Conceptual Change, and Argumentation Behavior}

In the researcher's classroom, a group of 3 students were heterogeneously placed together. The researchers found that a fierce argument broke out among one group of students during their dialogic argumentation! This symbolizes the unstable state of students' concept ecological— which indicted the initiation of the classroom argumentation; students' concept learning and conceptual change also took place gradually. Due to the research text length limitation, the researcher focused on discussing the dialogues of one group of students, and gave separate analysis to each question in the unit.

1) Students' performances in "understanding integer division, especially: $0 \leq$ remainder< |divisor|"

In light of this learning purpose, the researchers designed the questions: "Given the Division Axiom:

$$
a=b \bullet q+r(0 \leq r<|b|)
$$

Solve: 1) The quotient and remainder of 31 divided by 4, 2) The quotient and remainder of 100 divided by -13 "

Next, the researchers analyzed the students' dialogues based on Hewson's (1996) Conceptual ecology and Toulmin's argumentative model:

\section{1) Students' conceptual ecology development process}

From students' concept learning process of this question, the researchers found: when learning a mathematics concept, it was necessary for students to think it intelligible, plausible, and even fruitful, so as to stimulate actual, meaningful learning. This phenomenon echoed Skemp's (1971) relational understanding theory: knowing and knowing why meaning that one not only knew the reasons and principals of mathematic concept, but could also deduct and apply - which was true meaningful learning. Furthermore, these three students' concept development took form in different ways.

This echoed Vygotsky's argument that the cognitive function of constructive knowledge was the product of social interaction, and that the development of individual cognition began with external social activities and terminated in intrinsic individual activities. Accordingly, the researchers analyzed the three student's discussions above (Fig. 4).

In Fig. 5, the development of students' concept ecology could be categorized into two types: 1) had previously held concepts, but flawed - student 1 and 3 both held their own prior, yet flawed concepts. However, in the course of discussion, peer's questioning shakened their belief in the concept, which aroused dissatisfaction in students' state of concept ecology, and propelled them to reconstruct their concept comprehension. 2) Did not hold prior concepts student 2 did not have a profound understanding of this concept. Nevertheless, through peer interaction, she began her concept construction. 


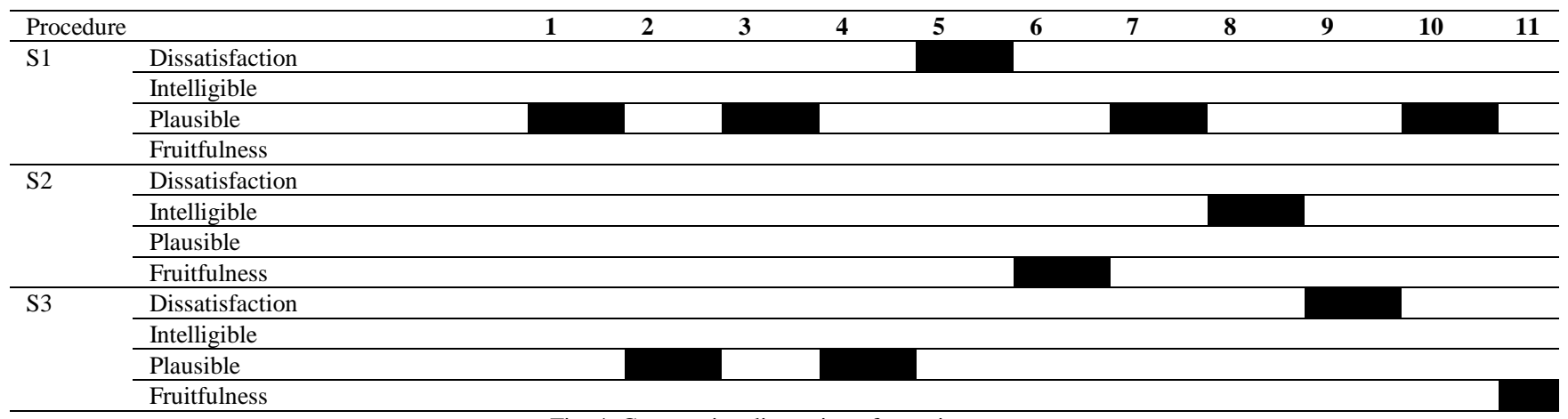

Fig. 4. Cooperative discussion of question one.

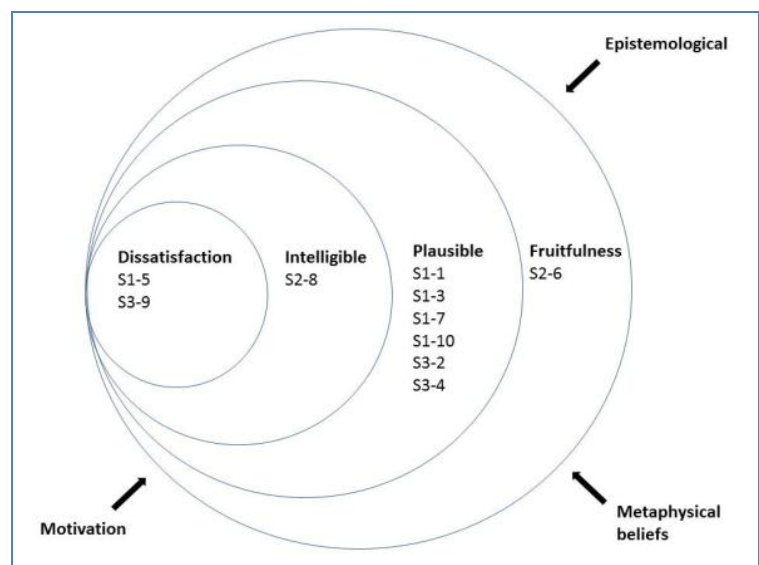

Fig. 5. Students' learning process of question 1(Coding: Student code-process)

\section{2) Students' argumentation content}

This indicted that: teachers must modify their teaching according to students' different argumentation method in order to achieve the effectiveness of classroom demonstration and concept of learning. The researchers analyzed students' conversation based on Toulmin's argumentation model shown below (Fig. 6).

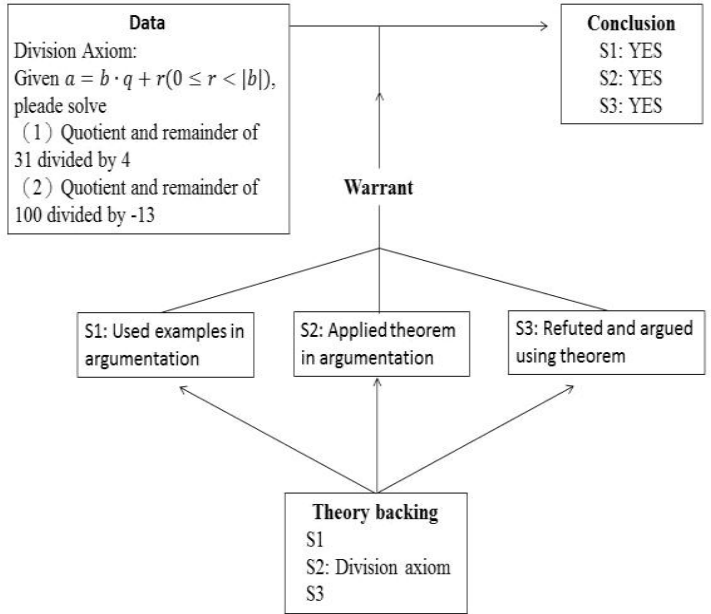

Fig. 6. Diagram of students' argumentation of the first question.

2) Students' "understanding the contrasting idea of factors and multiples and their properties."

Based on this learning purpose, the researchers designed the questions: " $a, b, c \in N$, if $a \mid b c$, then were $a \mid b$ or $a \mid c$ true? Please explain your reason.

\begin{tabular}{|c|c|c|c|c|c|c|c|c|c|c|c|c|c|c|c|}
\hline \multicolumn{2}{|c|}{ Procedure } & 1 & 2 & 3 & 4 & 5 & 6 & 7 & 8 & 9 & 10 & 11 & 12 & 13 & 14 \\
\hline \multirow[t]{4}{*}{ S1 } & Dissatisfaction & & & & & & & & & & & & & & \\
\hline & Intelligible & & & & & & & & & & & & & & \\
\hline & Plausible & & & & & & & & & & & & & & \\
\hline & Fruitfulness & & & & & & & & & & & & & & \\
\hline \multirow[t]{4}{*}{ S2 } & Dissatisfaction & & & & & & & & & & & & & & \\
\hline & Intelligible & & & & & & & & & & & & & & \\
\hline & Plausible & & & & & & & & & & & & & & \\
\hline & Fruitfulness & & & & & & & & & & & & & & \\
\hline \multirow[t]{4}{*}{ S3 } & Dissatisfaction & & & & & & & & & & & & & & \\
\hline & Intelligible & & & & & & & & & & & & & & \\
\hline & Plausible & & & & & & & & & & & & & & \\
\hline & Fruitfulness & & & & & & & & & & & & & & \\
\hline
\end{tabular}

Fig. 7. Cooperative discussion process of question 2 .

Next, the researchers analyzed the students' dialogues based on Hewson's (1996) [7] Conceptual ecology and Toulmin's argumentative model:

\section{3) Students' concept ecology development}

Using actual examples to refute against the other's argument conformed to mathematical justification. Therefore, the researchers believe: practice using examples in demonstration and contradicting opponents' arguments were necessary for students to learn mathematical justification. Furthermore, when students were contradicted with actual examples, their concept ecology fluctuated and became unstable; and thus easy to cause concept structure remodeling. Accordingly, the researchers arranged the three students' discussion below (Fig. 7).

Accordingly, the researchers characterize the three students' concept ecology below (Fig. 8). As showed in Fig. 8, the three students' concept development could be characterized into three types: 1) previously held correct concept- student 3 previously held this correct type of concept. Through peer discussion, she (student 3 ) tried to convince her peers to accept her ideas by giving examples and logical reasoning, and ultimately stimulated her friends' 
concept learning; 2) previously held flawed concept student 1 had previously learned the factor theorem, but her concept was incomplete, but through successive discussion with student 3 , student 3 generated her dissatisfaction toward her prior knowledge and achieved conceptual change; 3) Original concept hoding - student 2 did not have any clear idea or preconception, yet through peer discussion and guidance, this concept gradually took shape and furthur refined through thinking and deduction, and finally understood the concept.

\section{4) Students' argumentation content}

The three students' performances on this question reconfirmed that teachers must adjust their teaching based on students' different argumentation techniques in order to achieve effective classroom demonstration and concept learning. The researchers analyzed students' conversation using Toulmin's argumentation model below (Fig. 9).

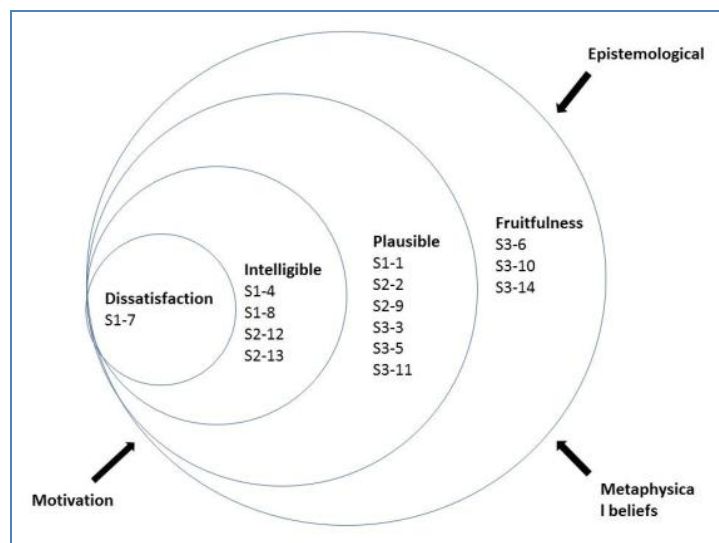

Fig. 8. Students' question 2 learning process (Coding: Student code-process).

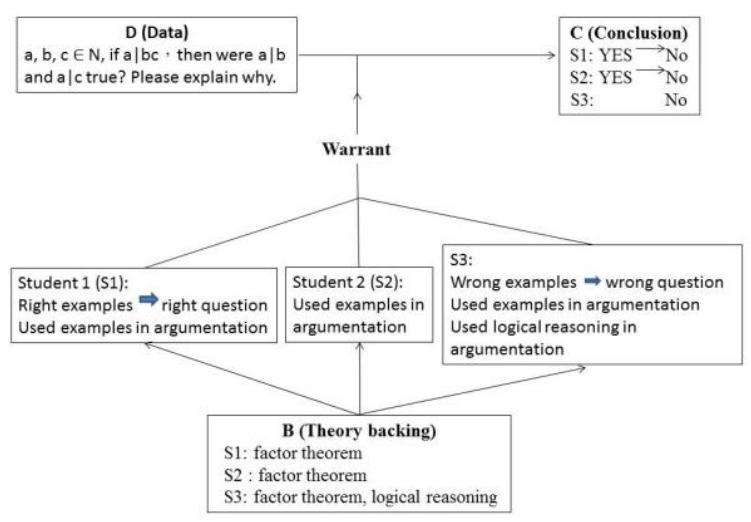

Fig. 9. Analysis of students' argumentation of question 2.

\section{B. Discussion of Students' Mathematic Concept Learning and Conceptual Change Mechanism and Argumentation Orientation}

The discussion above showed students' performances in concept learning and demonstration; researchers then analyzed individual student's concept learning path and demonstrate style, and went on to speculate possible factors that promoted concept learning, conceptual change, and argumentation behaviors (Table V).

1) Students' concept learning mechanism

The researchers found that: students' concept learning could be categorized into three types: 1) previously held correct concept-such students could always face new problems smoothly and learn without difficulty. Their conceptual status roamed between "intelligible," "plausible," and "fruitful" (e.g. students 3- question 2). In terms of Lakatos's scientific research theory, this was the strengthening of the hard core. 2) Previously held flawed correct concept - such students in concept learning would easily cause their own concept ecology instability when facing new situations or when challenged by their peers, and thus remodeled their previous concept. Their conceptual status underwent "dissatisfaction" (e.g. student 1- question 2; students 3- question 1). In terms of Lakatos's scientific research theory, it was the continued assailment of their protect area and the ultimate destruction of the hard core. This result resonate with Piaget: the schema disequilibrium was a fundamental factor in promoting cognitive changes. 3) Have no preconception toward the concept - such students could learn new concepts through peer discussion (e.g. student 2question 1,2). Therefore, the researchers speculated that possible mechanism influencing students' concept learning and conceptual change was "plausible explanation" and "dissatisfaction." In view of this, the researchers highlighted the results of concept learning mechanisms in this research below (Fig. 10).

TABLE V: STUDENTS' CONCEPT LEARNING AND ARGUMENTATION FACTOR SPECUlATION Chart (*D-Dissatisfaction; I-INTELligible; P-Plausible; F-FRUITFULNESS)

\begin{tabular}{|c|c|c|c|c|}
\hline $\mathbf{S}$ & $\begin{array}{l}\text { Concept } \\
\text { learning } \\
\text { path }\end{array}$ & $\begin{array}{l}\text { Demonstration } \\
\text { style }\end{array}$ & $\begin{array}{l}\text { Concept } \\
\text { learning } \\
\text { factor }\end{array}$ & $\begin{array}{l}\text { Argumentation } \\
\text { factor }\end{array}$ \\
\hline 1 & $\begin{array}{l}\text { Q1: } \\
\text { p-p-d-p-p } \\
\text { Q2: p-i-d-i }\end{array}$ & $\begin{array}{l}\text { Q1: example (4), } \\
\text { theorem (1) } \\
\text { Q2: example (3) }\end{array}$ & $\begin{array}{l}\text { Plausible } \\
\text { explanation } \\
\text { Dissatisfaction }\end{array}$ & $\begin{array}{l}\text { Example } \\
\text { Theorem }\end{array}$ \\
\hline 2 & $\begin{array}{l}\text { Q1: f-i } \\
\text { Q2: p-p-i-i }\end{array}$ & $\begin{array}{l}\text { Q1: example (1), } \\
\text { theorem (2) } \\
\text { Q2: example (1) }\end{array}$ & & \\
\hline 3 & $\begin{array}{l}\text { Q1: } \\
\text { p-p-d-f } \\
\text { Q2: } \\
\text { p-p-f-f-p-f }\end{array}$ & $\begin{array}{l}\text { Q1: example (4), } \\
\text { theorem (1) } \\
\text { Q2: example (3), } \\
\text { theorem (2) }\end{array}$ & & \\
\hline
\end{tabular}

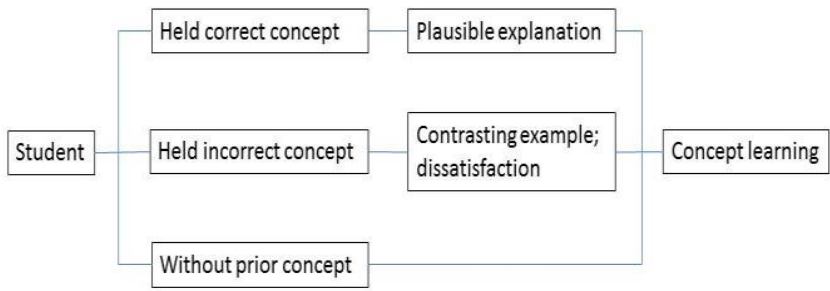

Fig. 10. Mathematics concept learning mechanism.

\section{2) ) Students' demonstration orientation}

The researchers found: students' demonstrate style could be divided into two types: 1) the tendency to use "example" in demonstration - either the "actual numerical structure" in question 1or the "abstract symbolic structure" in question 2; the majority of students inclined to use "example" to help them think and converse with their peers, and it also helped them in reasoning and making sense. 2) The tendency to use "theory" in demonstration - some students preferred to use "theory" as their argument basis, whereby to convince others, and such an approach helped to build students' reasoning 
power. 3) The tendency to use both "example" and "theory" in demonstration - students would also cross-use "example" and "theory" as their demonstration basis, to support their argument. Therefore, the researchers believed that what triggered classroom demonstration mechanism depended on whether teachers created a context for discussion which would boost peer argumentation. Only through teachers' constant encouragement would students be willing to presents their thoughts and arguments and enrich classroom demonstrate performances.

\section{CONCLUSION}

Through this study, researchers found: teaching is not just a means to inform or to demonstrate the use of knowledge to students; teachers must encourage students to create meaning through autonomous contemplation and deduction, reasoning and communication. Only by unbalancing the students' ecological concepts will they modify their present concept structure. For students, even when their conceptual ecology reached the "intelligible" level, it did not mean that would really use it; there might be two sets of standards within the students mind, and they would alternate between these two standards depending on the actual context (e.g. in an examination or in daily life) for explanation and justification. Therefore, how to enhance students' conceptual knowledge to the "plausible" or even the "fruitful" level is what all teacher should put great stress on. Furthermore, this study drew on Toulmin' argumentation model to analyze students' dialogues in mathematics classroom, and researchers found that: the mathematics class was abundant in argument connotation. In this study, students' argumentation orientation included using examples the use of theories in their demonstration. This result allowed the on-site teachers realized that: apart from preparing appropriate argumentative questions for students, teachers should further encourage students to think and to create an argumentative atmosphere, which could elevate the significance of in-class learning. However, all research has its own features and limitations; the researchers made the following suggestions for future reference and research:

\section{A. Did Individual Characteristics Particularize This Case Study?}

This research focused on studying a group of students selected from the researcher's own class and analyzing their conversation in a cooperative learning context. Students' demonstration orientation included the use of examples and theories; yet, could this result be generalized for all students? There should be post-tests to future studies to inspect the accuracy of this inference. Moreover, researchers selected the "numbers" unit from first-year high school material, but would students' performances differ if other learning material were selected? This also need to further study and analysis. Therefore, the researchers suggested future research to increase the number of participants, to enhance the value of the research inferences.

\section{B. Did Students' Learning Effectiveness Really Improved?}

From the results of this study researcher found that: in classroom demonstrations, peers' opposing and challenging examples often seemed to cause students' mathematics conceptual learning and change. Yet, could they perceive "plausibility" or even "fruitfulness? It seemed that post-tests were required to be able to give such verdict. Therefore, the researchers suggested that subsequent research to implement on this part to further understand students' learning.

\section{Are Clearer Measuring Tools Required for Concept Ecology Positioning?}

This research drew on the conceptual change model (Posner et al.) and the argumentative model (Toulmin) to study high school students' learning performance in the "numbers" chapter. Nevertheless, when the researchers were analyzing the collected data, they still applied Posner's theory to create the conceptual status analysis implement; strictly speaking, they could only clarify conceptual definition but operational definition, and thus, researchers suggested that subsequent research should take the operational definition validity into consideration to ensure the rigorousness of the research.

\section{REFERENCES}

[1] R. E. Slavin, "Student teams and achievement divisions," Journal of Research and Development in Education, no. 12, pp. 39-49, 1978.

[2] S. Toulmin, The Use of Argument, Cambridge: Cambridge University Press, 1958.

[3] J. Posner, K. Strike, P. Hewson, and W. Gertzog, "Accommodation of a scientific conception: Toward a theory of conceptual change," Science Education, no. 66, pp. 211-227, 1982.

[4] P. W. Hewson and M. G. A. Hewson, "The role of conceptual conflict in conceptual change and the design of science instruction,' Instructional Science, no. 13, pp. 1-13, 1984

[5] J. Nussbaum and A. Novick, "Alternative framework, conceptual conflict and accommodation: Toward a principled teaching strategy," Instructional Science, no. 11, pp. 183-200, 1982

[6] P. W. Hewson, Improving Teaching and Learning in Science and Mathematics, Teachers College, Teaching for Conceptual Change, Columbia University, 1996.

[7] S. E. B. Pirie and T. E. Kieren, "Growth in mathematical understanding: How can we characterise it and how can we represent it?" Educational Studies in Mathematics, no. 26, pp. 165-190, 1994.

[8] S. E. B. Pirie and T. E. Kieren, "A recursive theory of mathematical understanding," For the Learning of Mathematics, vol. 9, no. 3, pp. 7-II, 1989.

[9] National Council of Teachers of Mathematics, Principles and Standards for School Mathematics, National Council of Teachers of Mathematics, 2000.

[10] J. Confrey, "For the learning of mathematics," A theory of intellectual development (Part 1), vol. 14, no. 3, pp. 2-8, 1994.

[11] E. Labinowicz, Learning from Children: New Beginnings for Teaching Numerical Thinking: A Piagetian Approach, Menlo Park, CA: Addison-Wesley, 1985.

[12] T. Wood, "Creating a context for argument in mathematics class," Journal of Research in Mathematics Education, vol. 30, no. 2, pp. 171-191, 1999.

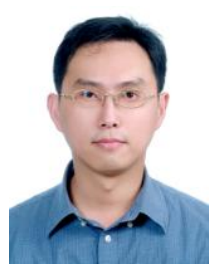

Yen-Ting Chen is an associate professor with the Department of Mathematics Education, National Taichung University of Education. His research interests are in mathematics education, e-learning, teacher education. He has been served as an assistan professor in Chung Hwa University of Medical Technology, and has also served as an assistan researcher in National Institute of Compilation and Translation and in National Academy for Educational Research.

Nowadays, he is an associate professor in the Department of Mathematics Education, National Taichung University of Education. During ten years, he was engaged in kindergarten instructor training, mathematics textbooks, mathematics curriculum reviewed and formulated, and researched in mathematics and science teachers how to interaction through internet platform. From 2008 till now, he has received subsidy from Taiwan's National Science Council (NSC) research grant researches. 
His research topics included preschool education, math and science teacher education, digital education, and attended conference to issue papers, and published journals papers etc. more than one hundred. He has issued related books or papers, such as science teacher in Asia.

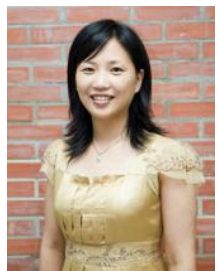

Juei-Hsin Wang is a professor and the director of Graduate Institute of Educational Administration and Policy Development, National Chiayi University. Her research interests are in education policy, teacher education, e-learning. She was an assistant professor in National Chiayi University, and served as the section chief of administrative of Teacher Education Center in 2007. From 2007 to 2013, She was an associate professor in Teacher Education Center and Graduate Institute of Educational Administration and Policy Development. Nowadays, she was promoted to be a professor since 2013
During ten years, She was involved in university teaching, research, service and local counseling. From 2009 till now, She is working as the director of professional training center of Teacher for Professional Development (Yuling, Chiayi, and Tainan region) of Ministry of Education in Taiwan. From 2004 till now, she has received subsidy from Taiwan's National Science Council (NSC) research grant researches.

Juei-Hsin Wang' research topics included educational policy, educational administration, teacher education, sexual equality on education, digital education, and attended conferences to issue papers, and published journals papers etc. more than one hundred papers. She has issued related books or papers, such as gender equality on education, teaching materials and methods for the course of activity of elementary schools, Higher Education system of the U.S., teacher evaluation, and training how to be a scientific teacher etc. 